A YIETEROGENEOUS-EXPECTATIIONS MODEL OF THE VALUE OF BONDS BEARING CALL OPTIONS

Zvi Bodie

Benjamin M. Friedman

Working Paper No. 218

NATIONAL BUREAU OF ECONOMIC RESEARCH, INC.

575. Technology Square

Cambridge, líassachusetts 02139

December 1977

This paper has not undergone the review accorded official NEER publications; in particular, it has not been submitted for approval by the Board of Directors. 
A HETEROGENEOUS-EXPECTATIONS MODEL OF THE VALUE OF BONDS BEARING CALL OPTIONS

Zvi Bodie and Benjamin M. Friedman

\begin{abstract}
This paper develops a dynamic programming model of the optimal refunding strategy and the corresponding value of a callable bond. The model differs from previous work on this subject primarily in that it explicitly admits the possibility of differences between the issuer's expectations of future interest rates and an investor's corresponding expectations. This generalization facilitates the application of the model to determine what a specific bond (issued, for example, by a particular corporation) is worth to any given investor. Additional analytical features of the model, which differ from corresponding aspects of some previous models, include the use of a stochastic discounting rate and the use of continuous distributions to characterize the relevant interest rate expectations.

For the bond issuer, his own expectations (together with the bond's coupon and call features) suffice to indicate the critical refunding yield as well as the expected value of the bond in each time period until the bond matures. For an investor, however, the analytical solution of the model and the illustrative numerical examples presented in the paper show that the issuer's expectations and the investor's own both matter if the two differ.
\end{abstract}




\section{A HETEROGENEOUS-EXPECTATIONS MODEL OF THE VALUE OF BONDS BEARING CALL OPTIONS}

Zvi Bodie and Benjamin M. Friedman*

Long-term corporate bonds, in modern times the primary vehicle of corporate external financing in the United States, are not pure bonds. Instead, the security issued by a corporation and purchased by investors consists of a bond less an option, retained by the issuer, to call the bond at a specified price after some specified deferment period. ${ }^{1}$ In recent years, therefore, the bond call option itself has understandably attracted substantial attention. As callable debt has constituted an ever greater component of many major companies' balance sheets, whether or not to exercise the call options on specific bonds has come to be an important element in corporate financial decision making. Similarly, as the volume of outstanding corporate bonds has grown to $\$ 350$ billion -- in comparison, for example, with a total market value of $\$ 850$ billion for all corporate equities -- investors have had ample incentive to develop techniques for evaluating these bonds, including their call features, as carefully as possible. 2

Pye's [20] seminal contribution a decade ago used a dynamic programming methodology to solve a problem which simultaneously determined the bond issuer's optimal refunding strategy and the corresponding value of the bond. In order to solve this problem, Pye assumed a finite time horizon, risk neutrality, and a discrete interest rate distribution with a finite number of states. Subsequent researchers have extended Pye's analysis in a number of ways. ${ }^{3}$ Elton and Gruber [ 9] and Kraus [16], for example, showed the 
implications of introducing an infinite horizon. In addition, they and other writers considered the practically relevant case which constrains the issuer to finance a refunding operation with a new issue of long-term bonds. Most recently, Brennan and Schwartz [ 6] have applied the option-pricing methodology of Merton [18] and Black and Scholes [ 3] under the assumption of a specific dynamic stochastic process generating interest rates.

The object of this paper is to develop a model of the optimal refunding strategy and the corresponding value of a callable bond which differs from previous work on this subject primarily in that it explicitly admits the possibility of differences between the issuer's expectations of future interest rates and an investor's corresponding expectations. This generalization facilitates the application of the model to determine what a specific bond (issued by a particular corporation) is worth to any given investor. As is now typical in the literature of bond refunding, ${ }^{4}$ the model takes as a given constraint that, in the event of a call, the issuer will finance the refunding with a new issue of long-term bonds; in contrast to some familiar work on this problem, however, the model developed here admits a stochastic discounting rate. $^{5}$ In addition, the model assumes, analogously to some previous work, that interest rate expectations -- including both the issuer's and the investor's, if the two differ -- are characterized by continuous, rather than discrete distributions; continuous distributions not only are probably more realistic but also are especially convenient in the context of applications of the model to market data to draw inferences about market participants' expectations. 6 
Section I indicates the general principles and specific assumptions underlying the optimal refunding and valuation model for callable bonds. Section II develops the model in full for the general case involving no specific assumption about how the issuer finances a refunding, and section III develops the model under the long-term refinancing constraint. Section IV illustrates several of the model's key properties, including the implications of differing issuer and investor expectations, by applying the model to several hypothetical examples based on the standard call features used in the U.S. corporate bond market. Section V briefly summarizes the paper's principal conclusions and suggests directions for further research. 
I. Introductory Remarks

The value of a bond subject to a call option equals the value of an otherwise identical noncallable bond less the value of the call option.

The value of the option to the option holder -- the issuer in the case of a callable bond -- follows from a decision problem in which the option holder maximizes an objective, subject to both the specified characteristics of the option itself and his expectations of the relevant future prices (or interest rates). At any moment of time, a bond issuer with callable bonds outstanding must decide whether or not to call the bonds. In an abstraction to a discrete-time model, the issuer must decide, at the beginning of each time period, whether to call the bonds or to leave them outstanding until the beginning of the next time period. Calling a bond at the beginning of time period $t$ implies an immediate payment of $c_{t}$ the current call price, while not calling the bond implies a payment of coupon $k$ at the end of the current time period $t$ and a new decision at the beginning of the subsequent time period $t+1$

The value of the option to the option writer -- the investor in the case of a callable bond -- is somewhat more complicated. Even given the investor's own objective and expectations of the relevant future prices (or interest rates), the value of the option to the investor depends upon actions to be taken at the sole discretion of the issuer (the option holder). To evaluate the option, therefore, the investor must second-guess the issuer's decisions, and to perform this task the investor must in turn have beliefs about the issuer's objective and expectations. ${ }^{8}$

Two convenient assumptions about the behavior of the firm facilitate 
modeling the issuer's optimal decision. First, in order to abstract from considerations relating to the firm's production, sales, and investment decisions, it is useful to assume that the firm makes the call decision independently of the "revenue" side of its activities. Secondly, in order to have a decision criterion, it is useful to assume that the objective determining the call decision is to minimize the present discounted value of the expected stream of payments associated with the outstanding bond (or its refinancing replacement). 9 The value of a callable bond to the issuer as of the beginning of time period $t$ is therefore

$$
v_{t}=\min \left\{C_{t}, \frac{1}{1+\rho_{t}}\left[k+E_{t}\left(\tilde{v}_{t+1}\right)\right]\right\}
$$

where $\rho_{t}$ is the time rate of discount which prevails in time period $t, E_{t}$ indicates an expectation as of the beginning of time period $t$, and the tilde symbol recalls that $\tilde{v}_{t+1}$ is a random variable as of the beginning of time period $t$. The appearance of $\tilde{v}_{t+1}$ in one of the two alternative expressions for $v_{t}$ immediately suggests a recursion relation requiring solution by dynamic programming.

An assumption about the investor's behavior is analogously necessary in order to calculate the value of the bond to the investor. If the investor is also a present value maximizer, then the value of a callable bond to the investor as of the beginning of time period $t$ is

$$
v_{t}^{\prime}=\min \left\{c_{t^{\prime}} \frac{1}{1+\rho_{t}^{\prime}}\left[k+E_{t}^{\prime}\left(\tilde{V}_{t+1}^{\prime}\right)\right]\right\}
$$

where all variables are as in (1) and the prime symbol indicates the value, discount rate and expectation pertaining to the investor, should any or all of these differ from the issuer's. 
The importance of expectations of future yields emerges clearly in the explicit evaluation of the expectation on the right-hand side of (1),

$$
E_{t}\left(\tilde{V}_{t+1}\right)={ }_{t}{ }_{t+1} \cdot C_{t+1}+\left(1-{ }_{t} P_{t+1}\right) \cdot E_{t}\left[\frac{1}{1+\tilde{\rho}_{t+1}}\left(k+E_{t+1}\left(\tilde{V}_{t+2}\right)\right)\right]
$$

where $t_{t+1}$ is the probability, assessed as of the beginning of time period $t$, that the optimal decision at the beginning of time period $t+1$ will be to refund the bond. Hence the expectation $E_{t}\left(\tilde{V}_{t+1}\right)$ equals the linear combination of the known call price $C_{t+1}$, premultiplied by probability $t_{t+1}{ }^{\prime}$ and the conditional expectation of the value of the bond in the event that the optimal decision at the beginning of time period $t+1$ is not to refund it, premultiplied by probability $\left(1-t_{t+1}^{P}\right)$. One element of that conditional expectation is in turn $E_{t+1}\left(\tilde{V}_{t+2}\right)$-- the expectation, as of the beginning of time period $t+1$, of the value of the bond at the beginning of yet the next time period, once again conditional on the issuer's optimal decision being not to refund the bond, in either of time periods $t$ or $t+l$. The explicit evaluation of that conditional expectation, in turn, continues the sequence analogously. A similar sequence emerges from explicit evaluation of the expectation $E_{t}^{\prime}\left(\tilde{V}_{t+1}^{\prime}\right)$ on the right-hand side of ( $\left.1^{\prime}\right)$.

Finally, the model developed in sections II and III below abstracts from default risk, as well as from tax considerations such as the differential tax treatment of the payment (or receipt) of interest versus call premiums. 


\section{The General Model}

For a conventional bond, the terminal condition which anchors the dynamic programming solution to the issuer's optimal refunding problem is simply the statement of the bond's par-value maturity property,

$$
\mathrm{V}_{\mathrm{T}+1}=1
$$

where $T$ denotes the final time period in the bond's term to maturity. The solution follows as a series of critical discount rate values $\rho_{T}^{*}, \rho_{T-1}^{*}, \ldots$, such that the optimal decision is to call the bond at the beginning of period $t$ if and only if $\rho_{t}<\rho_{t}^{*}$.

At the beginning of time period $T$, the issuer's problem in the general form (1) simply reduces to

$$
\mathrm{V}_{T}=\min \left\{\mathrm{C}_{\mathbf{T}^{\prime}} \frac{1}{1+p_{\mathbf{T}}}(k+1)\right\},
$$

and the solution to the minimization follows from comparing the newly emerged $\rho_{T}$ with the previously known coupon $k$ and call price $C_{T}$ to find the critical value

$$
\rho_{T}^{*}=\frac{k+1}{C_{T}}-1
$$

which equates the two alternatives within the right-hand side of (4). If $C_{T}=1$, as is typically the case (except for transactions costs) in U.S. corporate bond indentures, ${ }^{10}$ the critical value $\rho_{T}^{*}$ in (5) reduces to the bond's coupon rate $k$, so that the issuer's optimal refunding decision at the beginning of time period $T$ is to call the bond or not according to $\rho_{T} \$ k$.

For each subsequent time period $t, t=T-1, T-2, .$. (going backward), the general problem is simply (1) and its solution is 


$$
\rho_{t}^{*}=\frac{k+E_{t}\left(\tilde{V}_{t+1}\right)}{C_{t}}-1
$$

where, given the solution from the immediately prior (i.e., chronologically later) time period of the backward induction process,

$$
\begin{aligned}
E_{t}\left(\tilde{v}_{t+1}\right)= & C_{t+1} \int_{0}^{\rho}{ }^{*} f_{t+1}\left(\tilde{\rho}_{t+1}\right) d \rho \\
& +\left[k+E_{t+1}\left(\tilde{v}_{t+2}\right)\right] \int_{\rho_{t+1}^{*}}^{\infty} \frac{1}{1+\tilde{\rho}_{t+1}} f_{t}\left(\tilde{\rho}_{t+1}\right) d \rho .
\end{aligned}
$$

and $f_{t}\left(\tilde{\rho}_{\tau}\right), \tau=t+1, \ldots, T$, are independent probability density functions describing the issuer's expectations, as of time period $t$, about the (unknown) future path of the stochastic discount rate $\tilde{\rho}_{\tau} \cdot^{11}$

The T-th successive application of this procedure finally yields the new-issue value of the bond as

$$
v_{1}=\min \left\{c_{1}, \frac{1}{1+\rho_{1}}\left[k+E_{1}\left(\tilde{v}_{2}\right)\right]\right\}
$$

where

$$
E_{1}\left(\tilde{V}_{2}\right)=C_{2} \int_{0}^{\rho_{2}^{*}} f_{1}\left(\tilde{\rho}_{2}\right) d \rho+\left[k+E_{2}\left(\tilde{V}_{3}\right)\right] \int_{\rho_{2}^{*}}^{\infty} \frac{1}{1+\tilde{\rho}_{2}} f_{1}\left(\tilde{\rho}_{2}\right) d \rho
$$

On the assumption that bonds are issued at par, the new-issue value $v_{1}$ in (8) must presumably satisfy $v_{1} \leq 1$, or else the borrower would be unwilling to issue the new bonds in the first place.

In practice, all newly issued U.S. corporate bonds bear call options which come into effect only after some time interval, say D periods, after the issuance of the bond. In this case, the backward solution technique is 
relevant only as far as the beginning of time period $\mathrm{D}+1$, at which point

$$
v_{D+1}=\min \left\{C_{D+1}, \frac{1}{1+\rho_{D+1}}\left[k+E_{D+1}\left(\tilde{v}_{D+2}\right)\right]\right\}
$$

Solution of the issuer's refunding decision problem as in (1), (6) and (7) yields the previous period's expectation of the bond's value, as of the first call opportunity, as

$$
\begin{aligned}
E_{D}\left(\tilde{V}_{D+1}\right)= & C_{D+1} \int_{0}^{\rho_{D+1}^{*}} f_{D}\left(\tilde{\rho}_{D+1}\right) d \rho \\
& +\left[k+E_{D+1}\left(\tilde{V}_{D+2}\right)\right] \int_{\rho_{D+1}^{*}}^{\infty} f_{D}\left(\tilde{\rho}_{D+1}\right) d \rho .
\end{aligned}
$$

Since no call option is available at the beginning of time period $D$, however, the value of the bond at that time is simply

$$
v_{D}=\frac{1}{1+\rho_{D}}\left[k+E_{D}\left(\tilde{v}_{D+1}\right)\right]
$$

and the previous period's expectation of that value is simply

$$
E_{D-1}\left(\tilde{V}_{D}\right)=\left[k+E_{D}\left(\tilde{V}_{D+1}\right)\right] \int_{0}^{\infty} \frac{1}{1+\tilde{\rho}_{D}} E_{D-1}\left(\tilde{\rho}_{D}\right) d \rho .
$$

Successive application of this simple discounting procedure during the $\mathrm{D}$ time periods of deferment of the call option leads to the expression of the value of the bond in any time period $t=1, \ldots, D$, as ${ }^{12}$

$$
v_{t}=\frac{1}{1+\rho_{t}}\left[k+E_{t}\left(\tilde{v}_{t+1}\right)\right]
$$

where 


$$
E_{t}\left(\tilde{V}_{t+1}\right)=\left[k+E_{t+1}\left(\tilde{V}_{t+2}\right)\right] \int_{0}^{\infty} \frac{1}{1+\tilde{\rho}_{t+1}} f_{t}\left(\tilde{\rho}_{t+1}\right) d \rho .
$$

The D-th such successive discounting application finally yields the new-issue value of the deferred callable bond as

$$
\mathrm{v}_{1}=\frac{1}{1+\rho_{1}}\left[\mathrm{k}+\mathrm{E}_{1}\left(\tilde{\mathrm{v}}_{2}\right)\right]
$$

Once again, on the assumption that new bonds are issued at par, $v_{1}$ must satisfy $\mathrm{v}_{1} \leq 1$

It remains to consider the more complicated problem of determining the value of the bond to an investor whose relevant discount rate $\rho$ ' is not necessarily identical to discount rate $\rho$ which is relevant for the bond issuer, and whose interest rate expectations $f^{\prime}\left(\rho^{\prime}\right)$ and $f^{\prime}(\rho)$, may differ in unspecified ways from the issuer's expectations $f(\rho)$. Beginning the backward induction solution procedure in period $T$, as above, the value of the bond to the investor is

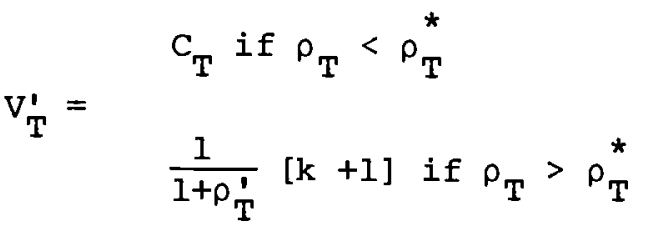

where $\rho_{\mathrm{T}}^{*}$ is as in (5).

For each subsequent time period $t=T-1, \ldots, D+1$, the general procedure for solving the investor's valuation problem is first to solve the issuer's decision problem (using the issuer's expectations $f(\rho)$ ) for the critical values $\rho_{t^{\prime}}^{*} t=D+1, \ldots, T$, and then to use these $\rho^{*}$ values as limits of integration in the straightforward evaluation of the expectation embracing the two 
alternative possibilities that the bond will or will not be called in any given time period $t=D+1, \ldots, T^{13}$ For any time period $t=D+1, \ldots, T$, the value of the bond to the investor as in (1') is therefore

$$
\begin{aligned}
& v_{t}^{\prime}=\quad C_{t} \text { if } \rho_{t}<\rho_{t}^{*} \\
& \frac{1}{1+\rho_{t}^{\prime}}\left[k+E_{t}^{\prime}\left(\tilde{V}_{t+1}^{\prime}\right)\right] \text { if } \rho_{t}>\rho_{t}^{*}
\end{aligned}
$$

where $\rho_{t}^{*}$ is as in (6) and

$$
\begin{aligned}
E_{t}^{\prime}\left(\tilde{V}_{t+1}\right)= & c_{t+1} \int_{0}^{\rho}{ }^{t+1} f_{t}^{\prime}\left(\tilde{\rho}_{t+1}\right) d \rho \\
& \left.+\left[k+E_{t+1}^{\prime}\left(\tilde{V}_{t+2}^{\prime}\right)\right] \int_{\rho_{t+1}^{*}}^{\infty} f_{t}^{\prime}\left(\tilde{\rho}_{t+1}\right) d \rho \cdot \int_{0}^{\infty} \frac{1}{1+\tilde{\rho}_{t+1}} f_{t}^{\prime} \tilde{\rho}_{t+1}^{\prime}\right) d \rho^{\prime} .
\end{aligned}
$$

Finally, for time periods $t=1, \ldots, D$, during which the call option deferment is in effect, the investor's discounting procedure is precisely analogous to that for the issuer in (14) and (15), substituting $f^{\prime}\left(\rho^{\prime}\right)$ for $f(\rho)$. On the assumption that new bonds are issued at par, $v_{i}$, the value to the investor at the time of issue, must satisfy $v_{1}^{1} \geq 1$. 
III. The Case of Long-Term Refinancing

A major obstacle to empirically implementing a general model of the issuer's optimal refunding decision like that developed in Section II is identifying the appropriate discounting rate $\rho$ to use in such calculations, and this question has received substantial attention in the literature. ${ }^{14}$ Some writers, for example, have argued that bond refunding is just another capital budgeting decision, so that $\rho$ properly represents the firm's average cost of capital. The consensus of the recent literature, however, is that $\rho$ should instead represent the currently prevailing market interest rate on the firm's outstanding long-term debt. The rationale usually cited in support of this choice is that the long-term debt yield properly reflects the risk of the cash flows being discounted. In addition, a further assumption which reinforces this choice is that the refunding decision with respect to outstanding long-term securities presupposes no change in the firm's liability structure in the sense of term to maturity (apart from call features). While this assumption in principle introduces some possibility for misunderstanding the issuer's refunding decision problem, it is probably not too far off the mark for practical purposes, since most issuers do in fact consider a refunding situation in the somewhat limited context of replacing outstanding long-term

bonds with a new issue of long-term bonds (presumably bearing a lower coupon).$^{15}$ In the context of the relationship between using the firm's cost of long-term debt in the optimal refunding calculation and assuming that a new long-term bond is the choice of refinancing vehicle, the primary question is whether this simplifying assumption introduces more or less possibility for misunderstanding or empirical irrelevance than does an alternative assumption identifying the 
relevant discount rate $\rho$ with some other specific observable variable.

Optimal refunding decision model (1) relies on an implicit two-fork decision tree approach in which, at the beginning of any time period $t$, the "terminal" (refund) fork is the immediate payment of call price $c_{t}$ while the "continuing" (do not refund) fork is the payment of coupon $k$ at the end of the time period (i.e., the beginning of the next time period) and a new decision then. If the issuer presupposes financing of the refunding by a new issue of long-term bonds, then the "terminal" fork is no longer an end point, and its value is not simply the call price but rather the stream of future payments of interest and principal on the newly issued security. It is therefore necessary to consider the coupon rate $k_{t}$ which, as of the beginning of time period $t$, is the market yield on new issues of the firm's long-term bonds. Furthermore, since new issues of immediately callable long-term bonds do not exist in the U.S. markets, it is appropriate to consider $k_{t}$ as the coupon rate on a new issue of long-term bonds bearing call options subject to deferral for some interval. 16

In the restricted context of a predetermined liability maturity structure, then, the issuer's refunding decision involves a comparison of the present value of two alternative streams of payments. One, as in (1), is the payment of coupon $\mathrm{k}$ for all time periods until the bond is called, with a new refunding decision possible in each successive time period. The other is the immediate payment of call price $C_{t}$, which requires simultaneously issuing a new bond in the amount of $C_{t}$, and subsequent payment of the new coupon $k_{t}$ for at least 
$D$ time periods (where $D$ is the length of the deferment period on the new bond's call option), with refunding decisions possible only in later time periods. The fixed-maturity analog to the issuer's refunding decision (1) is therefore

$$
v_{t}=\min \left\{R_{t}, \frac{1}{1+\rho_{t}}\left[k+E_{t}\left(\tilde{v}_{t+1}\right)\right]\right\}
$$

where the value of the stream of payments associated with the refinancing bond is $^{17}$

$$
\begin{aligned}
R_{t}=\frac{C_{t}}{1+\rho_{t}}\left\{k_{t}[1\right. & \left.+\sum_{\tau=t+1}^{T}\left(\prod_{s=t+1}^{\tau} \int_{0}^{\infty} \frac{1}{1+\tilde{\rho}_{s}} f_{t}\left(\tilde{\rho}_{s}\right) d \rho\right)\right] \\
& \left.+\underset{\tau=t+1}{T} \int_{0}^{\infty} \frac{1}{1+\tilde{\rho}} f_{t}\left(\tilde{\rho}_{\tau}\right) d \rho\right\} .
\end{aligned}
$$

The issuer's fixed-maturity refunding decision therefore involves two distinct sets of interest rate expectations, as is clear from considering the conditional expectation on the right-hand side of (17), 18

$$
E_{t}\left(\tilde{V}_{t+1}\right)={ }_{t}^{P}{ }_{t+1} \cdot E_{t}\left(\tilde{R}_{t+1}\right)+\frac{1-t^{P} t+1}{1+\rho_{t}}\left[k+E_{t+1}\left(\tilde{V}_{t+2}\right)\right] .
$$

As of the beginning of time period $t, k_{t}$ is known but $\tilde{k}_{t+1}$ is not. Hence $\tilde{R}_{t+1}$ is random, as of the beginning of time period $t$, because of uncertainty associated not only with future $\tilde{\rho}_{\tau}, \tau=t+1, \ldots, T$, but also with the future 
coupon rate $\tilde{k}_{t+1}$. The reason why expectations of future coupon rates enter the problem is the "lock-in" feature associated with the noncallability (or call option deferment) of the refinancing bonds. Refinancing with immediately callable bonds is not possible, and refinancing with noncallable bonds requires the issuer to pay coupon $k_{t}$ in every subsequent time period, regardless of the potential emergence of even lower new-issue coupon rates later on. ${ }^{19}$ Even if an issuer can refinance the outstanding k-coupon bonds by issuing new bonds with some coupon $k_{t}$ which is enough lower than $k$ to warrant paying the current call price, therefore, he may gain even more by waiting to refinance, say s time periods later, at the then-prevailing coupon rate $\tilde{k}_{t+s}$ which may be even less than $k_{t}$. It is this feature of the problem which gives the variance, or volatility, of future long-term newissue yields an added importance for the optimal refunding decision and the resulting value of the callable bond. Even if the issuer expects the longterm new-issue yield to be high in the future on average, if he expects this yield to be volatile he may value greatly the opportunity to refund at precisely the time when the yield has fallen below his expectation of its long-term average.

In complete form, therefore, the solution to the fixed-maturity refunding decision problem leads to a backward succession, from time period $T$, of expressions involving integration over two sets of density functions -- one for the discount rate and one for the coupon rate. Expectations about these two interest rates, however, are unlikely to be independent. A useful simplification which avoids altogether the need for two different sets of integrals is simply to assume that expectations about one rate are one-for-one equivalent 
to expectations about the other, i.e.,

$$
f_{t}\left(\tilde{\rho}_{t+s}\right)=f_{t}\left[g_{t+s}\left(\tilde{k}_{t+s}\right)\right], F_{t}\left(\tilde{k}_{t+s}\right)=F\left[g_{t+s}^{-1}\left(\tilde{\rho}_{t+s}\right)\right], \quad s>0,
$$

for some nonstochastic transformation $g_{t+s}(\cdot)$ for each time period $t+s$. Under this covariation assumption it is possible to restate the issuer's refunding decision problem in terms of expectations of future new-issue yields on long-term (noncallable) bonds, so that (18) becomes 20

$$
\begin{aligned}
R_{t}=\frac{C_{t}}{1+g_{t}\left(k_{t}\right)}\left\{k_{t}[1\right. & +\sum_{\tau=t+1}^{T}\left(\prod_{s=t+1}^{\tau} \int_{0}^{\infty} \frac{1}{1+g_{s}\left(\tilde{k}_{s}\right)} F_{t} \tilde{\left(k_{s}\right)} d k\right] \\
& \left.+\prod_{\tau=t+1}^{T} \int_{0}^{\infty} \frac{1}{1+g_{\tau}\left(\tilde{k}_{\tau}\right)} F_{t}\left(\tilde{k}_{\tau}\right) d k\right\},
\end{aligned}
$$

while the analogous expectation on the right-hand side of (19) becomes

$$
\begin{aligned}
E_{t}\left(\tilde{R}_{t+1}\right)= & C_{t+1} \int_{0}^{\infty} \frac{1}{1+g_{t+1}\left(\tilde{k}_{t+1}\right)}\left\{\tilde { k } _ { t + 1 } \left[1+\sum_{\tau=t+2}^{T}\left(\prod_{s=t+2}^{\tau} \int_{0}^{\infty} \frac{1}{1+g_{s}\left(\tilde{k}_{s}\right)} F_{t}\left(k_{s}\right) d k\right]\right.\right. \\
& \left.+\prod_{\tau=t+2}^{T} \int_{0}^{\infty} \frac{1}{1+g_{\tau}\left(\tilde{k}_{\tau}\right)} F_{t}\left(\tilde{k}_{\tau}\right) d k\right\} F_{t}\left(\tilde{k}_{t+1}\right) d k
\end{aligned}
$$

At the beginning of time period $T$, the problem is simply

$$
\mathrm{V}_{\mathrm{T}}=\min \left\{\mathrm{R}_{\mathrm{T}}, \frac{1}{1+\mathrm{g}_{\mathrm{T}}\left(\mathrm{k}_{\mathrm{T}}\right)}(\mathrm{k}+1)\right\}
$$

where, because $k_{T}$ is known, $R_{T}$ is the nonrandom

$$
R_{T}=\frac{C_{T}}{1+g_{T}\left(k_{T}\right)}\left(k_{T}+1\right) .
$$


The critical value $k_{T}^{*}$ follows, analogously to $\rho_{T}^{*}$ in $(4)$, as the new-issue rate which equates the two alternatives within the right-hand side of (23), and the optimal refunding decision is to call the bond or not according to $\mathrm{k}_{\mathrm{T}} \stackrel{\lessgtr}{>} \mathrm{k}_{\mathrm{T}}^{*}$. If $\mathrm{C}_{\mathrm{T}}=1$, then $\mathrm{k}_{\mathrm{T}}^{*}=\mathrm{k}_{\mathrm{T}^{\prime}}$, and the final-period refunding decision simply involves a comparison of the current (one-period) borrowing rate with the outstanding bond's coupon. 21

For each subsequent time period $t, t=T-1, \ldots, D+1$, the problem is just (17), where $R_{t}$ is as in (21),

$$
\begin{aligned}
E_{t}\left(\tilde{V}_{t+1}\right)= & \int_{0}^{k_{t+1}^{*}} R_{t+1} F_{t}\left(\tilde{k}_{t+1}\right) d k \\
& +\left[k+E_{t+1}\left(\tilde{V}_{t+2}\right)\right] \int_{k_{t+1}^{*}}^{\infty} \frac{1}{1+g_{t+1}\left(\tilde{k}_{t+1}\right)} F_{t}\left(\tilde{k}_{t+1}\right) d k,
\end{aligned}
$$

and the critical value $k_{t}^{*}$ follows as the $(T-t+1)$-period new-issue rate which equates the two alternatives within the right-hand side of (17). Following this procedure backward to the solution for $E_{D}\left(\tilde{V}_{D+1}\right)$, and then applying the simple discounting procedure of (14) and (15) for the earlier time periods during which the bond is noncallable, completes the solution of the issuer's fixed-maturity refunding problem.

Finally, as in the general model of section II, solving for the value of the bond to the investor requires first applying the procedure developed above (using the issuer's expectations $f(\rho)$ and $F(k)$ ) to solve the issuer's fixed-maturity refunding problem for the critical new-issue yields $k_{t}^{*}, t=$ $D+1, \ldots, T$. In the absence of any assumption about the investor's application 
of the proceeds of a call, the value of the bond for any time period $t=$ $\mathrm{D}+1, \ldots, \mathrm{T}$, then follows from re-evaluating the relevant probabilities of call on the basis of the investor's corresponding expectations $f^{\prime}(\rho)$ and $F^{\prime}(k)$ and the relevant discounted values on the basis of the investor's expectations $f^{\prime}\left(\rho^{\prime}\right)$, so that the expressions analogous to ( $\left(^{\prime}\right)$ and $\left(7^{\prime}\right)$ are

$$
\begin{aligned}
& c_{t} \text { if } k_{t}<k_{t}^{*} \\
& v_{t}^{\prime}= \\
& \frac{1}{1+\rho_{t}^{\prime}}\left[k_{t}+E_{t}^{\prime}\left(\tilde{V}_{t+1}^{\prime}\right)\right] \text { if } k_{t}>k_{t}^{*} \\
& E_{t}^{\prime}\left(\tilde{v}_{t+1}\right)=C_{t+1} \int_{0}^{k_{t+k}^{*}} F_{t}^{\prime}\left(\tilde{k}_{t+1}\right) d k \\
& +\left[k+E_{t+1}\left(\tilde{v}_{t+2}\right)\right] \int_{k_{t+1}^{*}}^{\infty} \frac{1}{1+g_{t+1}^{\prime}\left(\tilde{k}_{t+1}\right) d k}
\end{aligned}
$$

where $g^{\prime}(\cdot)$ is the transformation relating the investor's discount rate to the issuer's new-issue rate. Alternatively, under the assumption that the investor will apply the proceeds of the call to re-invest in the refinancing bond, the analogous expressions are

$$
\begin{aligned}
& R_{t}^{\prime} \text { if } k_{t}<k_{t}^{*} \\
& v_{t}^{\prime}= \\
& \frac{1}{1+p_{t}^{\prime}}\left[k+E^{\prime}\left(\tilde{v}_{t+1}\right)\right] \text { if } k_{t}>k_{t}^{*} \\
& E_{t}^{\prime}\left(\tilde{V}_{t+1}\right)=\int_{0}^{k_{t+1}^{*}} \tilde{R}_{t+1}^{\prime} F^{\prime}\left(\tilde{k}_{t+1}\right) d k \\
& \left.+\left[k+E_{t+1}^{\prime}\left(\tilde{V}_{t+2}^{\prime}\right)\right] \int_{k_{t+1}^{*}}^{\infty} \frac{1}{1+g_{t+1}^{\prime}\left(\tilde{k}_{t+1}\right)} F_{t}^{\prime} \tilde{k}_{t+1}\right) d k
\end{aligned}
$$


where 22

$$
\begin{aligned}
R_{t}^{\prime}=\frac{C_{t}}{1+g_{t}^{\prime}\left(k_{t}\right)}\left\{k _ { t } \left[1+\sum_{\tau=t+1}^{T}\left(\prod_{s=t+1}^{\tau} \int_{0}^{\infty} \frac{1}{1+g_{s}^{\prime}\left(\tilde{k}_{s}\right)} F_{t}^{\prime}\left(\tilde{k}_{s}\right) d k\right]\right.\right. \\
\\
\left.+\prod_{\tau=t+1}^{T} \int_{0}^{\infty} \frac{1}{1+g_{\tau}^{\prime}\left(\tilde{k}_{\tau}\right)} F_{t}^{\prime}\left(\tilde{k}_{\tau}\right) d k\right\} .
\end{aligned}
$$

For time periods $t=1, \ldots, D$, the value to the investor again follows from the simple discounting procedure indicated in section II. 


\section{Some Illustrations}

A few hypothetical examples may serve to illustrate some of the pertinent properties of the solutions yielded by the bond valuation and optimal refunding decision solution procedures developed above.

Consider, for example, a 25-year bond with a coupon of 88 per annum payable semi-annually. In addition, suppose that the relevant discounting rate is also $8 \%$ per annum, and that both the issuer and investors expect the market yield to continue to be 88 per annum. If the bond is noncallable, then the initial value is simply $100 .^{23}$ since the expected market yield is 8\% per annum for the next 25 years, the bond's expected price in any future period until maturity is also 100.

If the same 25-year $8 \%$ bond is callable, however, and if either the issuer or investors (or both) believe that the market yield may fall below 88 per annum at some point during the bond's 25-year life (i.e., there is some non-zero variance associated with the 88 expectation), then neither the initial value nor the expected price in any future time period before maturity equals 100. The income stream generated by this bond (and its replacement, in the event of refunding) will under no circumstances be greater than that of the initial 88 coupon rate. Because of the possibility of refunding, which in turn depends upon future interest rates and expectations thereof, this income stream may be less than that of the initial 88 coupon rate. Given a discounting factor of 88 , therefore, the bond's price will always be strictly less than 100, unless interest rate expectations are such as to preclude the possibility of refunding. 
The first two columns of Table 1 present the solution of the bond valuation and optimal refunding decision model of Section III for the case of the immediately callable 25-year $8 \%$ bond described immediately above. The key assumptions underlying this solution are that both the issuer's and investors' expectations of future coupon interest rates, $F\left(\tilde{k}_{t}\right)$ and $F^{\prime}\left(\tilde{k}_{t}\right), t=1: I I, \ldots$ $T(=25: I I)$ are characterized by a truncated normal distribution with mean 88 and standard deviation $18,{ }^{24}$ and that the expected relationship between the issuer's and investors' discounting rates $\left(\rho_{t}\right.$ and $\left.\rho_{t}^{\prime}\right)$ and coupon rate $k_{t}$ as in (19) is simply $\rho_{t}=\rho_{t}^{\prime}=k_{t}, t=1, \ldots, T$.

The first column of the table shows, for each half-year period during the first ten years and for alternative half-year periods thereafter, the critical refunding yield $k_{t}^{*}$ which follows as the $(T-t+1)$-period new-issue rate which equates the two alternatives within the right-hand side of (17). The issuer's optimal decision, at the beginning of time period $t$, is to refund the bond if $k_{t}<k_{t}^{*}$ and not to refund it if $k_{t}>k^{*}$. The monotonically increasing series of $k_{t}^{*}$ values shown in the first column of the table illustrates clearly the "lock-in" implication of a call-protected refinancing bond as emphasized in section III. In particular, it is not optimal to refund the outstanding bond at every coupon rate which satisfies $k_{t}<88$, even though doing so would lead to an interest saving. Unless $k_{t} \leq k_{t}^{*}<88$ (except for the final period), the present discounted value of the interest saving achieved by refunding at $k_{t}<88$ is smaller than the present discounted value of the expected interest saving from refunding in some later time period $t+\tau$ at the then-prevailing coupon rate $k_{t+\tau}<k_{t} \cdot 25$ Given the 
TABLE 1

CRITICAL REFUNDING YIELDS AND EXPECTED PRICES FOR CALLABLE 25-YEAR 8\% BONDS

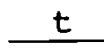

$1: I$

I:II

$2: I$

2 : II

$3: I$

$3:$ II

$4: I$

$4:$ II

$5: I$

5 : II

$6: I$

6:II

$7: I$

7:II

$8: I$

8:II

9:I

9:II

10:I

10:II

11: I

$12: I$

13:I

14:I

15:I

$16: I$

$17: I$

$18: I$

19:I

20:I

21: I

22 : I

23:I

24:I

25:I

25 : II

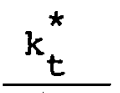

$6.57 \%$

6.58

6.58

6.59

6.60

6.60

6.61

6.62

6.62

6.63

6.64

6.65

6.66

6.66

6.67

6.68

6.69

6.70

6.71

6.72

6.74

6.76

6.78

6.82

6.85

6.88

6.92

6.96

7.01

7.08

7. 15

7. 24

7. 38

7.63

8.00
$E\left(\tilde{v}_{t}\right)=E^{\prime}\left(\tilde{v}_{t}^{\prime}\right)$

\begin{tabular}{lcc}
\hline $\begin{array}{c}\text { Immediately } \\
\text { Callable }\end{array}$ & Callable After & Callable After \\
& 5 Years & 10 Years \\
\hline
\end{tabular}

\subsection{5}

90.90

90.94

90.99

91.05

91.11

91.17

91.24

91.32

91.40

94.26

94.03

93.79

93.54

93.28

93.01

92.73

92.44

92.13

91.81

96.68

96.55

96.41

96.26

96.11

95.95

95.79

95.62

95.44

95.26

91.48

91.57

91.67

91.77

91.88

92.00

92.12

92.24

92.38

92.52

91.48

91.57

91.67

91.77

91.88

92.00

92.12

92.24

92.38

92.52

95.06

94.87

94.66

94.44

94.22

93.98

93.74

93.49

93.22

92.95

92.67

92.99

93.33

93.71

94.12

92.67

92.67

92.99

92.99

93.33

93. 71

93.33

93. 71

94.12

94.12

94.57

94.57

94.57

95.05

95.05

95.56

96.10

96.67

95.56

95.56

96.10

96.10

96.67

96.67

97.26

97.87

98.47

99.06

99.59

99.81
97.26

97.87

98.47

99.06

99.59

99.81
97.26

97.87

98.47

99.06

99.59

99.81

Assumptions: $\quad E\left(\tilde{k}_{t}\right)=E^{\prime}\left(\tilde{k}_{t}\right)=88, \sigma\left(\tilde{k}_{t}\right)=\sigma^{\prime}\left(\tilde{k}_{t}\right)=18, \rho_{t}=\rho_{t}^{\prime}=k_{t}$ all $t$. 
assumed constant mean and nonzero variance of the distributions describing expectations of future interest rates, the earlier is the time period $t$ the lower $k_{t}$ must be to justify refunding.

The second column of the table shows, for the same half-year periods, the price $v_{t}=v_{t}^{\prime}$ expected to prevail at the beginning of the period for this (immediately) callable 25-year $8 \%$ bond. The value of the bond's call option is the difference between this price and 100, which would be the expected price of a noncallable $8 \%$ bond. Given the assumed parameters of expectations of future interest rates, the immediately callable bond will sell for only 91.25 at its initial time of issue, so that the call option is initially worth 8.75. After the initial half-year period, the expected price $E\left(\tilde{V}_{t}\right)=E^{\prime}\left(V_{t}^{\prime}\right)$ increases monotonically with time period $t$, at a steadily growing rate of increase. The initial new-issue price is somewhat greater than the expected price at the beginning of the next several time periods because of the certainty of receiving the $8 \%$ coupon payment at the end of the first half year; within the simplified discrete-time framework of this paper, even the call option of an "immediately callable" bond is implicitly deferred for one time period.

As an illustration of more generally deferred call options, the third and fourth columns of Table 1 present analogous solution values for the expected prices of callable 25-year $8 \%$ bonds bearing the standard utility and industrial call deferments of five years and ten years, respectively, using the same assumptions about expectations of future interest rates which underlie the solution for the immediately callable bond. Once the five- or ten-year deferment period expires, the initially call-protected bond no longer 
differs from the immediately callable bond, so that the critical refunding yield and expected price series for time periods $t>D(=5:$ II or 10:II $)$ are identical to those shown in the first two columns of the table. For time periods $t=1, \ldots, D$, the critical refunding yield is undefined for a call-protected bond, and the expected price is greater than that of the immediately callable bond, since the coupon payments are certain to be at the $8 \%$ rate (i.e., the upper limit for the immediately callable bond). As the call deferment interval elapses, the expected price declines monotonically to reflect the decreasing number of certain $8 \%$ coupon payments. Figure 1 , which summarizes the expected price relationships among the immediately callable and two call-protected 25-year $8 \%$ bonds by plotting the three expected price series as functions of time period $t$, shows clearly how the different bonds become indistinguishable upon the expiration of the relevant call deferments.

Next, it is useful to consider explicitly the dependence of the results presented in Table 1 on the assumed uncertainty, characterized by standard deviation $\sigma\left(\tilde{k}_{t}\right)=\sigma^{\prime}(\tilde{k})=1 \%$, associated with expectations of future interest rates. Table 2 shows the relationship between the assumed standard deviation and the bond's new-issue price $v_{1}=V_{1}^{\prime}$ for four kinds of $8 \%$ 25-year bonds: immediately callable bonds (i.e., bonds callable after the first half year), bonds callable after five years, bonds callable after ten years, and noncallable bonds. ${ }^{26}$ For a given set of call provisions (except for the noncallable bond ${ }^{27}$, the greater is the uncertainty the lower is the bond's price. Conversely, for given uncertainty, the earlier the bond is callable the lower is its price. 


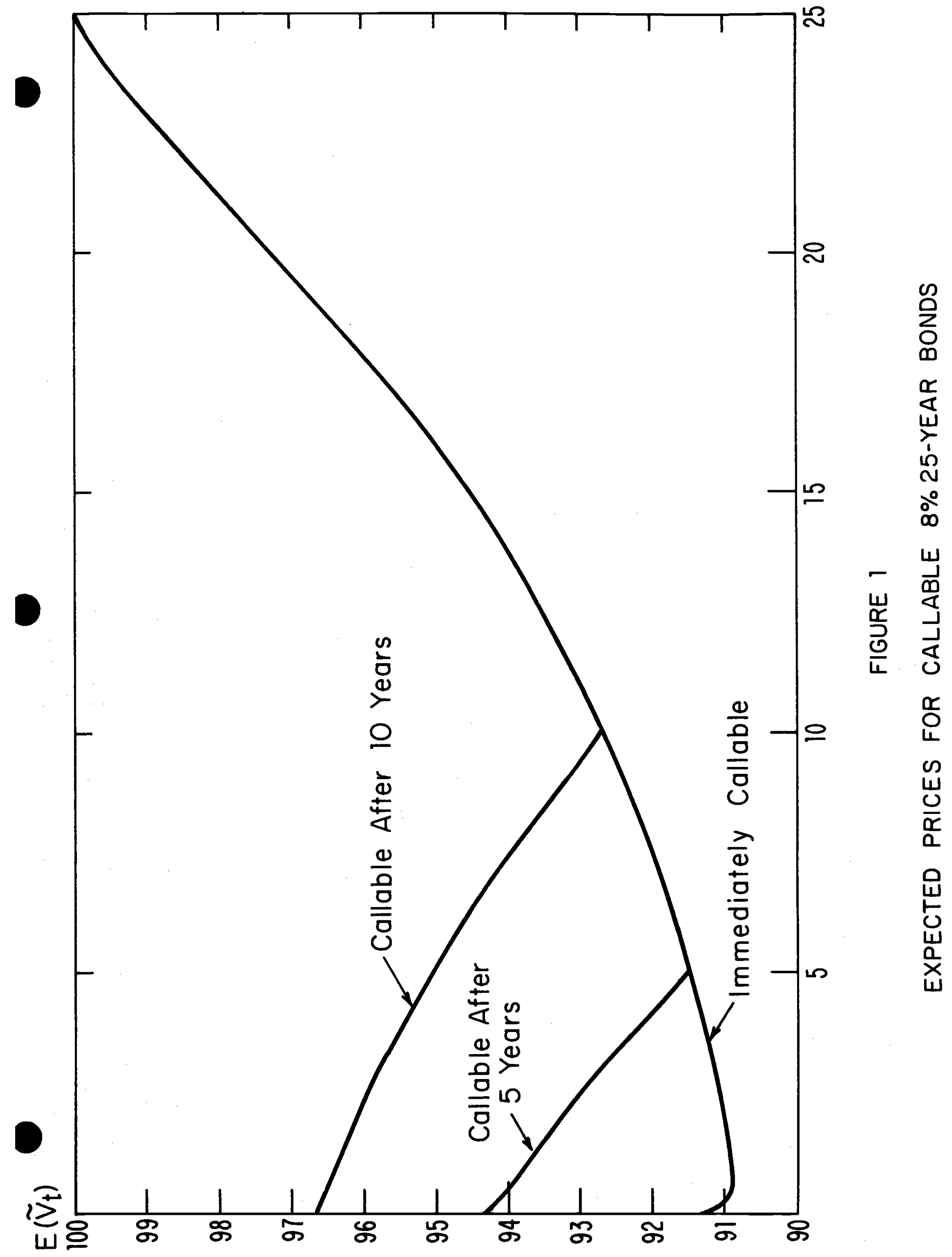


TABLE 2

NEW-ISSUE PRICES OF CALLABLE AND NONCALLABLE

$8 \%$ 25-YEAR BONDS UNDER HOMOGENEOUS EXPECTATIONS

$\sigma\left(\tilde{k}_{t}\right)=\sigma^{\prime}\left(\tilde{k}_{t}\right)$

\begin{tabular}{l}
$\begin{array}{c}\text { Immediately } \\
\text { Callable }\end{array}$ \\
\hline
\end{tabular}

Callable After

Callable After

Noncallable

0.28

99.93

99.94

99.94

100.00

0.58

97.55

98.27

98.93

100.01

$1.0 \%$

91.25

94.26

96.68

100.05

$1.5 \%$

84.59

90.09

94.38

100.11

$2.0 \%$

77.86

85.88

92.07

100.20

$2.5 \%$

71.09

81.66

89.76

100.31

Assumptions: $\quad E^{\tilde{k}}\left(\tilde{t}^{\prime}\right)=E^{\prime}\left(\tilde{k}_{t}\right)=8 \%, \rho_{t}=\rho_{t}^{\prime}=k_{t}$, all $t$. 
Table 3 presents analogous results for the general circumstance in which $\sigma\left(\tilde{k}_{t}\right)$, the standard deviation which the issuer associates with expectations of future interest rates, differs from the investor's corresponding standard deviation for the single case of a 25-year $8 \%$ bond callable after five years. The entries along the diagonal of the table, for which $\sigma\left(\tilde{k}_{t}\right)=\sigma^{\prime}\left(\tilde{k}_{t}\right)$, are identical to those in the second column of Table 2. When the issuer and the investor disagree, however -- i.e., off the table's diagonal -- the results differ sharply. Given the issuer's expectations, the greater is the issuer's uncertainty the lower is the bond's price. By contrast, given the investor's expectations, the bond's price is lowest when the issuer agrees -- i.e., when $\sigma\left(\tilde{k}_{t}\right)=\sigma^{\prime}\left(\tilde{k}_{t}\right)$; and the greater the disagreement the higher the price, regardless of the direction of the disagreement (although the rate of increase is asymmetrical).

Because the $8 \%$ coupon of all of the callable bonds considered in Tables 1-3 is identical to the assumed mean of the distribution of expected future interest rates $E\left(\tilde{k}_{t}\right)=E^{\prime}\left(\tilde{k}_{t}\right)$, and because these expectations are not held with perfect certainty, the expected prices of all three of these bonds are always less than 100, even at the time of issue. By contrast, in the United States as well as in most other countries, new long-term bonds are typically issued at or near 100 even when they bear call options. Since a coupon rate equal to the mean of stationary expectations of future market discount rates results in callable bond prices less than 100, some coupon rate greater than this mean is necessary to make the callable bond worth 100 at the time of issue. For any given set of stationary expectations of future interest rates, the amount by which the coupon rate must exceed the fixed mean depends 
TABLE 3

NEW-ISSUE PRICES OF A 5-YEAR NONCALLABLE

$8 \%$ 25-YEAR BOND UNDER HETEROGENEOUS EXPECTATIONS

$\sigma\left(k_{t}\right)$

$\underline{0.58}$

1.08

$1.5 \%$

$\underline{2.08}$

0.58

98.27

95.26

92.60

89.97

1.08

99.34

94.26

90.85

88.01

1.58

99.90

95.42

90.09

86.49

2.08

99.97

97.64

90.97

85.88 
not only upon the bond's call features but also, following the model developed above, upon the higher moments of the density functions describing interest rate expectations.

Table 4 and Figure 2 summarize the implications of the bond refunding and valuation model for bonds having the same call provisions as those assumed in Table 1 but different coupons, under the same assumptions about interest rate expectations as in Table $1 .{ }^{28}$ The first two columns of Table 4 show the critical refunding yields and the expected prices for an immediately callable 25-year $10.60 \%$ bond. As the first entry in the price column indicates, $10.60 \%$ is precisely the coupon rate necessary to render the bond's new-issue price equal to 100 , given the bond's call provisions and given the issuer's and investors' expectations of future interest rates characterized by truncated normal distributions with $\mathrm{E}\left(\tilde{\mathrm{k}}_{t}\right)=\mathrm{E}^{\prime}\left(\tilde{\mathrm{k}}_{t}\right)=88$ and $\sigma\left(\tilde{\mathrm{k}}_{t}\right)=\sigma^{\prime}\left(\tilde{\mathrm{k}}_{t}\right)$ $=18$. As in the example in Table 1 , the critical refunding yield $k_{t}^{*}$ (also plotted as the solid line in panel (a) of Figure 2) in the first column of Table 4 rises monotonically so that it equals 10.608, the bond's coupon rate, in the final half year of the bond's term to maturity. Since the mean interest rate expectation is well below the $10.60 \%$ coupon rate, the critical refunding yield remains far below $10.60 z$ - indeed below $E\left(\tilde{k}_{t}\right)=E^{\prime}\left(\tilde{k}_{t}\right)=8 z$ -- until only three years before the bond's maturity. The bond's expected price (also plotted as the solid line in panel (b) of Figure 2) declines for seven years -- with the largest decline coming after the first half year, when the implicit one-period call deferment expires -- then rises until shortly before the bond's maturity, and finally declines back to 100 . 
TABLE 4

CRITICAL REFUNDING YIELDS AND EXPECTED PRICES FOR

CALLABLE 25-YEAR BONDS ISSUED AT PAR

\begin{tabular}{|c|c|c|c|c|c|c|}
\hline \multirow[b]{2}{*}{$t$} & \multicolumn{2}{|c|}{$\begin{array}{l}10.60 \% \text { Bond } \\
\text { Immediately } \\
\text { Callable } \\
\end{array}$} & \multicolumn{2}{|c|}{$\begin{array}{c}8.92 \% \text { Bond } \\
\text { Callable After } \\
5 \text { Years } \\
\end{array}$} & \multicolumn{2}{|c|}{$\begin{array}{c}8.408 \text { Bond } \\
\text { Callable After } \\
10 \text { Years } \\
\end{array}$} \\
\hline & $k_{t}^{*}$ & $E\left(\tilde{v}_{t}\right)$ & $k_{t}^{*}$ & $E\left(\tilde{v}_{t}\right)$ & $k_{t}^{*}$ & $E\left(\tilde{v}_{t}\right)$ \\
\hline $1: I$ & - & 100.00 & - & 100.00 & - & 100.00 \\
\hline I:II & 7.138 & 98.74 & - & 99.54 & - & 99.82 \\
\hline $2: I$ & 7.14 & 98.69 & - & 99.06 & - & 99.60 \\
\hline $2:$ II & 7.14 & 98.65 & - & 98.56 & - & 99.38 \\
\hline $3: I$ & 7.15 & 98.61 & - & 98.04 & - & 99.15 \\
\hline $3:$ II & 7.16 & 98.57 & - & 97.50 & - & 98.91 \\
\hline $4: I$ & 7.17 & 98.54 & - & 96.93 & - & 98.65 \\
\hline $4: I I$ & 7.17 & 98.51 & - & 96.35 & - & 98.39 \\
\hline $5: I$ & 7.18 & 98.49 & - & 95.74 & - & 98.12 \\
\hline $5: I I$ & 7.19 & 98.47 & - & 95.11 & - & 97.84 \\
\hline $6: I$ & 7.20 & 98.45 & 6.88 & 94.45 & - & 97.55 \\
\hline $6:$ II & 7.21 & 98.43 & 6.89 & 94.50 & - & 97.24 \\
\hline $7: I$ & 7.22 & 98.42 & 6.90 & 94.55 & - & 96.92 \\
\hline $7:$ II & 7.23 & 98.42 & 6.91 & 94.61 & - & 96.59 \\
\hline $8: I$ & 7.24 & 98.42 & 6.92 & 94.68 & - & 96.25 \\
\hline $8: I I$ & 7.25 & 98.42 & 6.93 & 94.75 & - & 95.89 \\
\hline $9: I$ & 7.26 & 98.43 & 6.93 & 94.82 & - & 95.51 \\
\hline 9:II & 7.27 & 98.44 & 6.94 & 94.90 & - & 95.13 \\
\hline $10: I$ & 7.28 & 98.45 & 6.95 & 94.99 & - & 94.73 \\
\hline $10:$ II & 7.30 & 98.47 & 6.96 & 95.08 & - & 94.31 \\
\hline $11: I$ & 7.31 & 98.50 & 6.97 & 95.18 & 6.84 & 93.88 \\
\hline $12: I$ & 7.33 & 98.56 & 7.00 & 95.40 & 6.87 & 94.15 \\
\hline $13: I$ & 7.36 & 98.65 & 7.03 & 95.64 & 6.89 & 94.45 \\
\hline $14: I$ & 7.40 & 98.75 & 7.06 & 95.91 & 6.92 & 94.77 \\
\hline $15: I$ & 7.44 & 98.88 & 7.09 & 96.20 & 6.95 & 95.13 \\
\hline $16: I$ & 7.48 & 99.02 & 7.12 & 96.52 & 6.98 & 95.52 \\
\hline $17: I$ & 7.53 & 99.18 & 7.16 & 96.87 & 7.02 & 95.93 \\
\hline 18:I & 7.58 & 99.35 & 7.21 & 97.24 & 7.06 & 96.38 \\
\hline $19: I$ & 7.65 & 99.54 & 7.26 & 97.64 & 7.11 & 96.85 \\
\hline $20: I$ & 7.73 & 99.72 & 7.33 & 98.05 & 7.17 & 97.35 \\
\hline $21: I$ & 7.83 & 99.91 & 7.41 & 98.47 & 7.23 & 97.86 \\
\hline $22: I$ & 7.97 & 100.07 & 7.51 & 98.90 & 7.32 & 98.38 \\
\hline $23: I$ & 8.15 & 100.20 & 7.64 & 99.30 & 7.44 & 98.89 \\
\hline $24: I$ & 8.45 & 100.25 & 7.84 & 99.66 & 7.60 & 99.36 \\
\hline $25: I$ & 9.09 & 100.14 & 8.23 & 99.90 & 7.92 & 99.75 \\
\hline $25:$ II & 10.60 & 100.00 & 8.92 & 99.95 & 8.40 & 99.89 \\
\hline
\end{tabular}

Assumptions: $\quad E\left(\tilde{k}_{t}\right)=E^{\prime}\left(\tilde{k}_{t}\right)=8 z, \sigma\left(\tilde{k}_{t}\right)=\sigma^{\prime}\left(\tilde{k}_{t}\right)=18, \rho_{t}=\rho_{t}^{\prime}=k_{t^{\prime}}$ all $t$. 


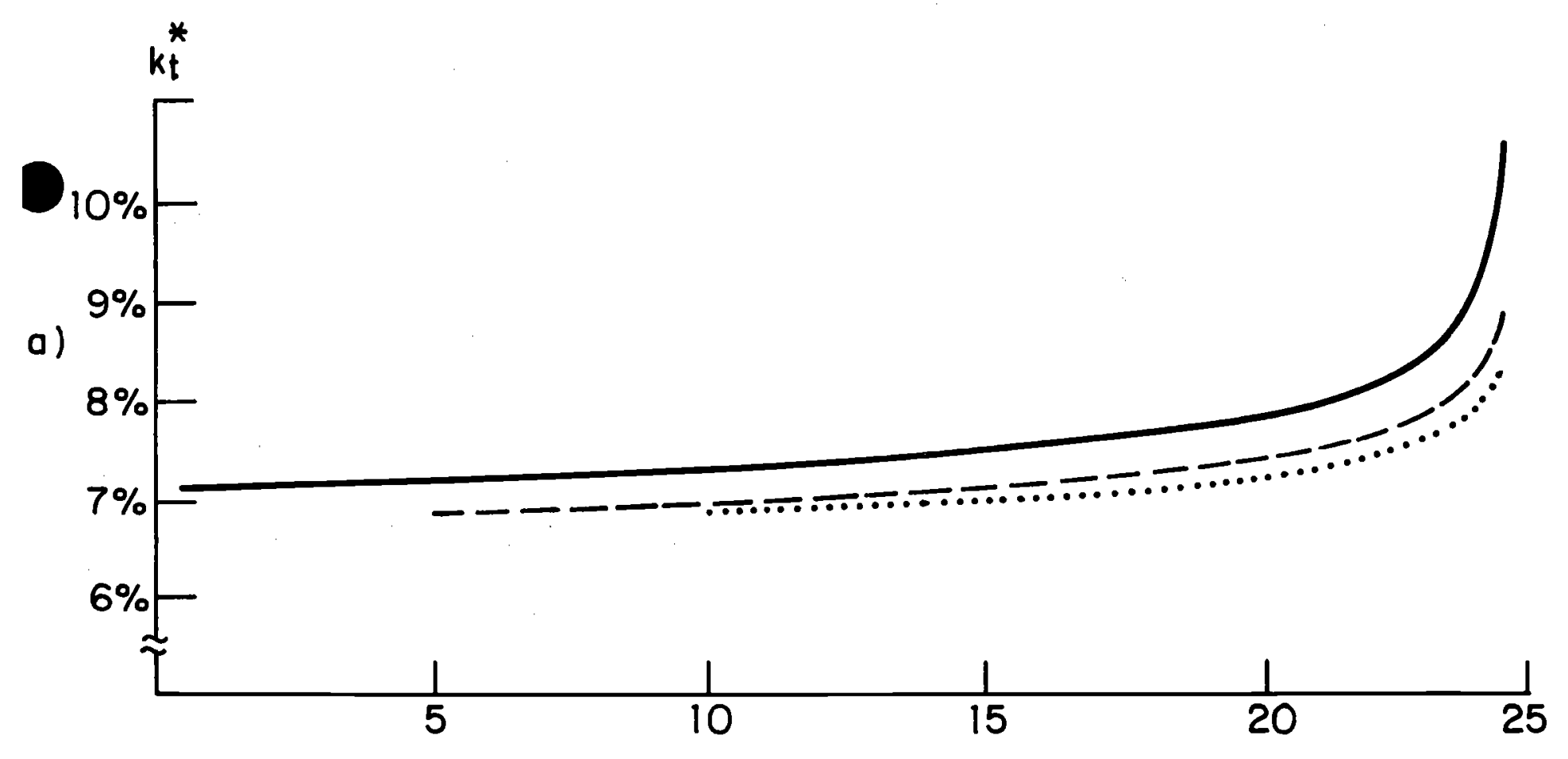

Callable Immediately (10.60\% Coupon)

- - Callable After 5 Years ( $8.92 \%$ Coupon)

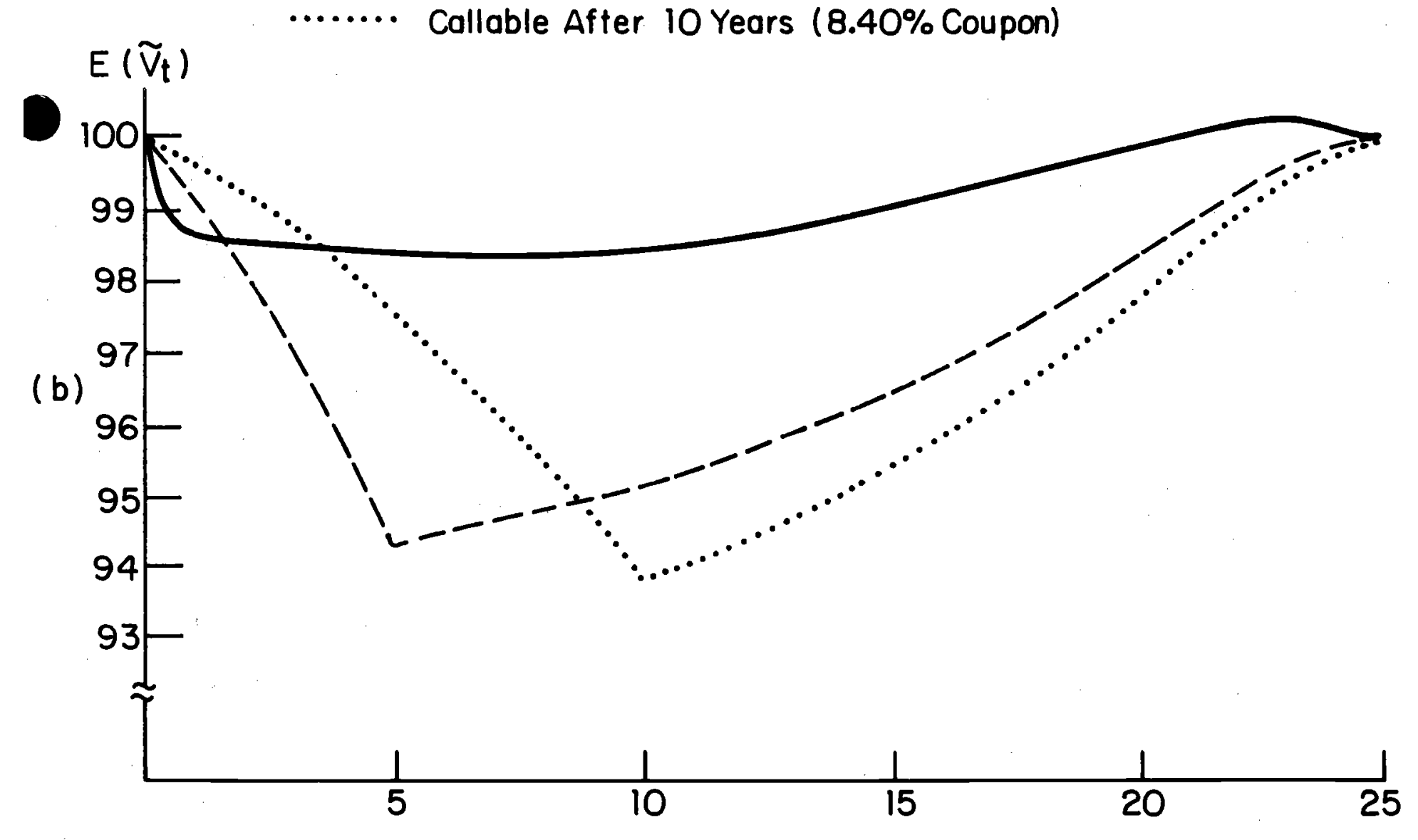

FIGURE 2

CRITICAL REFUNDING YIELDS AND EXPECTED PRICES FOR 25-YEAR BONDS ISSUED AT PAR 
The remaining columns of Table 4 , and the broken and dotted lines in Figure 2, show the analogous $\mathrm{k}_{t}^{*}$ and $E\left(\tilde{V}_{t}\right)$ solution values for a 25-year $8.92 \%$ bond callable after five years and a 25-year $8.40 \%$ bond callable after 10 years. Because of the series of certain coupon payments guaranteed by their respective call deferments, the coupon rates necessary to render these bonds' new-issue prices equal to 100 are less than for the immediately callable bond, and the ten-year call-protected bond requires a lower coupon rate for this purpose than does the five-year call-protected bond. The two callprotected bonds' respective critical refunding yields, which are defined only for time periods after the expiration of their call deferments, again rise monotonically to equal the respective coupon rates in the final half year of the bonds' term to maturity. In contrast to the examples in Table 1 , however, in which the three bonds depicted each have the same coupon rate and therefore have the same $k_{t}^{*}$ series, in Table 4 the different coupon rates on the three bonds imply different $k_{t}^{*}$ series for each. The expected price series for the five- and ten-year call-protected bonds shown in Table 4 decline monotonically until the respective bonds become callable, and then rise monotonically until the bonds' maturity, according to the pattern familiar from Table 1. Once again, however, because the three bonds illustrated in Table 4 bear different coupons, their expected price series also differ throughout. In particular, since it has the lowest coupon (8.40\%), the price of the ten-year call-protected bond falls to the lowest level of any of the three bonds illustrated in Table 4.

Finally, Table 5 summarizes the implications of interest rate uncertainty for the coupon rate necessary to render a bond's new-issue price equal to 100 . 
TABLE 5

COUPON RATES REQUIRED FOR PAR NEW-ISSUE PRICE

FOR CALLABLE AND NONCALTABLE 25-YEAR BONDS

\begin{tabular}{|c|c|c|c|c|}
\hline$\sigma\left(\tilde{k}_{t}\right)=\sigma^{\prime}\left(\tilde{k}_{t}\right)$ & $\begin{array}{c}\text { Immediately } \\
\text { Callable } \\
\end{array}$ & $\begin{array}{c}\text { Callable After } \\
5 \text { Years } \\
\end{array}$ & $\begin{array}{c}\text { Callable After } \\
10 \text { Years } \\
\end{array}$ & Noncallable \\
\hline 0.28 & 8.008 & 8.008 & $8.00 \%$ & 8.008 \\
\hline $0.5 \%$ & 8.48 & 8.25 & 8.12 & 8.00 \\
\hline 1.08 & 10.60 & 8.92 & 8.40 & 8.00 \\
\hline 1.58 & 13.18 & 9.65 & 8.70 & 7.99 \\
\hline $2.0 \%$ & 16.00 & 10.40 & 9.00 & 7.98 \\
\hline 2.58 & 19.03 & 11.14 & 9.30 & 7.97 \\
\hline
\end{tabular}

Assumptions: $\quad E\left(\tilde{k}_{t}\right)=E^{\prime}\left(\tilde{k}_{t}\right)=88, \rho_{t}=\rho^{\prime}{ }_{t}=k_{t^{\prime}}$ all $t$. 
As in Table 2, the computations underlying Table 5 assume homogeneous issuer's and investors' expectations with mean $8 \%$. In contrast to the examples in Table 2, however, in which the four bonds depicted all have 88 coupon rates so that the callable bonds have new-issue prices below 100, in Table 5 the four bonds' respective coupon rates differ according to whatever coupon is necessary for a par new-issue price. Following the same logic which indicates new-issue prices less than 100 for the three $8 \%$ callable bonds in Table 2, the callable bonds in Table 5 all have coupon rates greater than $8 \%$. For a given set of call provisions (except for the noncallable bond ${ }^{29}$ ), the greater the uncertainty the higher is the required coupon rate. Conversely, for given expectations, the earlier the bond is callable the higher is the required coupon rate. 
v. Summary of Conclusions

Expectations about future interest rates are essential to the bond issuer's optimal refunding problem and the associated problem of determining the value of a callable bond. For the issuer, his own expectations (together with the bond's coupon and call features) suffice to indicate the critical refunding yield as well as the expected value of the bond in each time period until the bond matures. For an investor, however, the issuer's expectations and his own both matter if the two differ.

In the general refunding decision and callable bond valuation model developed in Section II, in which there is no specific presumption about how the issuer finances a refunding operation, the relevant interest rate expectations refer only to the issuer's and investor's respective discounting rates. In the less general -- but probably more important for practical applications -- model developed in Section III, in which the issuer finances the refunding by issuing a new long-term (call deferred) bond, the relevant interest rate expectations refer not only to the issuer's and investor's respective discounting rates but also to the new-issue rate on the issuer's long-term bonds. Once again, if an investor's expectations about the future course of this interest rate differ from the issuer's, both sets of expectations are relevant to determining the value of the bond to an investor. The hypothetical examples presented in section IV illustrate the relationship, within the model, of both the mean and the associated uncertainty of the issuer's and investors' interest rate expectations for a number of the model's parameters including the bond's coupon, call deferment, critical refunding yield, newissue price, and expected price in future time periods. 
A number of simplifying assumptions in the analysis of this paper probably represent interesting topics for further research. The use in the illustrations in Section IV of a constant discounting factor mean, for example, is equivalent to the assumption of a flat term structure of interest rates. To the extent that yields on debts of different term to maturity differ, the individual coupon payments should be discounted by different factors. Since the actually prevailing term structure is typically fairly flat after the first several years, the approximation involved in assuming a totally flat term structure probably leads to significant over-valuation or under-valuation only for the first few coupon payments. Nevertheless, the assumption itself is merely convenient and is in no way a necessary element of the model, so that allowing for any specified non-flat term structure would be straightforward, as would allowing for any specified non-flat (probably increasing) standard deviation.

A second subject for further research along these lines concerns risk aversion. While the model's assessments of probabilities explicitly incorporate the full distributions of interest rate expectations, its valuations rely only on expected values and ignore preferences with respect to higher moments. Allowing for risk aversion would simply require substituting any specified utility function for the simple present discounted value function applied in Sections II and III.

Yet a third extension of the model would be to replace the normal distributions used in section IV to characterize interest rate expectations with different (perhaps asymmetrical) distributions. Here again, the assumption of normally distributed expectations is in no way necessary for the model, and substituting an alternative distribution would be straightforward. 
Finally, the model admits a variety of potentially interesting empirical applications, including not only direct use as an aid to corporations' financial decisions and/or investors' portfolio decisions but also use in reverse to infer market participants' (unobservable) expectations from observed market data. 30 
Footnotes

* The authors are, respectively, Assistant Professor of Economics and Finance, Boston University School of Management, and Associate Professor of Economics, Harvard University. They are grateful to Richard Cohn, Robert Glauber, Peter Jones, Jay Light, John Lintner, Huston McCulloch, and Franco Modigliani for helpful comments. Support of Friedman's research by the National Science Foundation and the National Bureau of Economic Research is gratefully acknowledged.

1. The security is the bond less the option, because in effect the purchaser of the bond is required to write an option to the issuer, permitting the issuer to call the bond, i.e., to repay the loan. Industrial bonds and utility bonds almost always bear ten years and five years, respectively, of call protection.

2. Data are from Board of Governors of the Federal Reserve System, Flow of Funds Accounts, and are as of yearend 1976.

3. In addition to the references cited in the text, see also Bowlin [ 5], Pye [21], Jen and Wert [13], and ofer and Taggart [19]. For an analysis which antedated Pye's, see Crockett's Appendix to Hess and Winn [11].

4. See, for example, the treatment in Elton and Gruber [10].

5. For analysis of the bond refunding problem, assuming a nonstochastic discount rate misses the heart of the problem, and both Pye and Elton and Gruber [ 9] incorporated a stochastic discount rate in their respective models. By contrast, much of the literature analyzing the refunding option has been deficient in assuming a nonstochastic discount rate; see, for example, Kraus [16], Kalymon [14] and Elton and Gruber [10].

6. See Bodie and Friedman [ 4].

7. To the extent that the refunding operation involves transactions costs, such as investment bankers' fees or use of management time, $C_{t}$ includes these costs as well as the call price per se.

8. The model developed in this paper abstracts from a number of complications which arise from the option writer's need to estimate the option holder's objective and expectations, e.g., the "gaming" implications which would result if bond issuers and investors deliberately attempted to conceal their true objective and expectations from one another; see Cyert and de Groot [7, 8] for a treatment of an analogous problem in a different context.

9. Other objectives, perhaps incorporating risk aversion, would also be suitable, both here and below for the investor. The only requirement, which follows from the use of dynamic programming to solve the model, is that the objective function exhibit the intertemporal separability (additivity) property; for reference, see Bellman [1] and Bellman and Dreyfus [ 2]. In conjunction with a further assumption extending the present discounted value criterion to other aspects of the issuer's behavior, this objective is consistent with maximization of stockholders' wealth. 
10. The call price typically provides for some premium above the bond's principal amount, with that premium varying positively with the number of years remaining to maturity at the time of exercise of the call option. One commonly used schedule of call prices, for example, begins at $100 \%$ of principal amount plus one year's coupon interest, if the bond is called within one year of its issue, and declines linearly to $100 \%$ of principal amount some few years before maturity.

11. No general solution exists for the refunding decision problem when expectations of the stochastic discount rate are state-dependent. To solve this problem, therefore, it is necessary to specify a unique . stochastic process which the issuer assumes to generate the future $\rho \tau$ ' so that the resulting solution depends on the particular stochastic $\tau$ process chosen. Pye [20] dealt with this problem by assuming that the discount rate followed a first-order Markov process, with a small number of possible states, and using either estimated values or arbitrarily assigned values for the elements of the transition matrix. The stateindependence assumption introduced above renders the problem solvable by straightforward dynamic programming techniques while still permitting a general form for the density functions $f_{t}\left(\tilde{\rho}_{\tau}\right)$.

12. Successive application of the time discounting procedure in (14) and (15), for a given set of expectations about the future discount rate, of course yields a form of the familiar expectations hypothesis of the term structure of interest rates; see Hicks [12] and Lutz [17].

13. Integrals $\int_{0}^{\rho_{t}^{*}} f_{t-1}^{\prime}\left(\tilde{\rho}_{t}\right) d \rho$ and $\int_{\rho_{t}^{*}}^{\infty} f_{t-1}^{\prime}\left(\tilde{\rho}_{t}\right) d \rho$ represent the investor's perception of probabilities analogous to $t^{P} t+1$ and $\left(1-t^{P}{ }_{t+1}\right)$, respectively, as in (2).

14. See, for example, Bowlin [ 5], Ofer and Taggart [19], and the references cited therein.

15. More precisely, issuers most often use a refunding situation to extend somewhat the maturity of their outstanding debt; Elton and Gruber's [ 9] generalization of Pye's model focuses on this point.

16. U.S. issuers of long-term corporate bonds almost always issue bonds bearing call options deferred for either five or ten years, depending on the business of the issuer. Issuers refunding bonds which originally bore five-year call deferments will typically issue new bonds bearing five-year deferments. Issuers refunding bonds which originally bore ten-year deferments will typically issue new bonds bearing ten-year deferments.

17. This simplified expression overstates $R_{t}$ in that it does not take account of the possibility of subsequently calling the refinancing bond before maturity. The correct expression is 


$$
\begin{aligned}
R_{t}=\frac{C_{t}}{1+\rho_{t}}\left\{k_{t}[1\right. & \left.+\sum_{=t+1}^{t+D}\left(\prod_{s=t+1}^{\tau} \int_{0}^{\infty} \frac{1}{1+\tilde{\rho}_{s}} f_{t}\left(\tilde{\rho}_{s}\right) d s\right)\right] \\
& \left.+E_{t+D}\left(\tilde{R}_{t+D+1}\right) \cdot \prod_{\tau=t+1}^{t+D} \int_{0}^{\infty} \frac{1}{1+\tilde{\rho}_{s}} f_{t}\left(\tilde{\rho}_{s}\right) d s\right\}
\end{aligned}
$$

where $E_{t+D}\left(\tilde{R}_{t+D+1}\right)$ follows from a further backward induction solution analogous to that shown below except using $k_{t}$ in place of $k$, and expressions (21) and (21') below are analogously altered. Hence the model is in general able to accommodate an entire series of potential refundings, as would be the case for $D$ small relative to $T$. The possibility of multiple refundings, however, means that the computational requirements of the solution no longer increase only linearly with $T$.

18. Once again, this expectation is conditional on the bond's not being called as of the beginning of time period $t$.

19. The problem is therefore similar to the optimal one-time sale of an asset in the context of an uncertain stream of bids; see, for example, Karlin's [15] highly instructive treatment of that question.

20. See again footnote 17.

21. For the later periods of the outstanding bond's term (i.e., the first periods treated in the backward induction), the term to maturity of the refinancing bond to be issued is very short under the fixed-maturity assumption. For the limiting case of the final time period $T$ as in (22) and (23), for example, $k_{\mathrm{T}}$ is a one-period borrowing rate, so that the discounting rate is $g_{T}\left(k_{T} T=k_{T}\right.$. For discount rates of the order of those in the numerical examples presented below, however, any termstructure implications of this aspect of the fixed-maturity assumption in far-off time periods have only very small effects on the resulting calculations for current refunding decisions and valuations.

22. See again footnote 17 .

23. Footnote 27 below qualifies this statement.

24. The normal distribution is truncated so as to preclude expectations of negative nominal interest rates.

25. Note that $C_{t}>100$ provides yet another reason, apart from interest rate expectations, why it may not be optimal to refund at $k_{t}<10.608$. The effect of a declining call price, so that $C_{t+\tau}<c_{t}$, could be to make it optimal to wait to refund even if $k_{t+\tau} \geq k_{t}$. 
26. The remaining assumptions underlying the solution values presented in Table 1 are the same as those used in Figure 1, including flat, normally distributed expectations with $E\left(\tilde{k}_{t}\right)=E^{\prime}\left(\tilde{k}_{t}\right)=8 \%$ for all $t$ and truncated so as to preclude expectations of negative nominal interest rates.

27. Because $E\left(\frac{1}{1+\tilde{k}_{t}}\right)>\frac{1}{1+E\left(\tilde{k}_{t}\right)}$ for $\left(\tilde{k}_{t}\right)>0$ (Jensen's Inequality), there is always a small effect in the opposite direction, i.e., requiring a higher price as $\sigma\left(\tilde{k}_{t}\right)$ becomes larger. For callable bonds, the effect of $\sigma\left(\tilde{k}_{t}\right)>0$ on the valuation of the call option predominates. For noncallable bonds, the smaller (opposite) effect stands alone. As the "noncallable" column of Table 2 indicates, however, this effect is quantitatively very small for normally distributed interest rate expectations.

28. In each case the schedule of call prices declines linearly from 100 plus one year's interest in the first half year to 100 in the final half year of the bond's term to maturity.

29. The reason for the coupon rates less than $8 \%$ for the noncallable bond is again the effect of Jensen's Inequality; see again footnote 26 .

30. See Bodie and Friedman [ 4] for an application of the model in reverse, to market data for 1969-76, to infer the uncertainty associated with expectations of future interest rates. 
$\underline{\text { References }}$

1. Bellman, Richard E. Dynamic Programming. Princeton: Princeton University Press, 1957.

2. Bellman, Richard E., and Dreyfus, stuart E. Applied Dynamic Programming. Princeton: Princeton University Press, 1962.

3. Black, Fischer, and Scholes, Myron. "The Pricing of Options and Corporate Liabilities." Journal of Political Economy, LXXXI (May/June, 1973), 637-654.

4. Bodie, Zvi, and Friedman, Benjamin M. "Interest Rate Uncertainty and the Value of Bond Call Protection." Journal of Political Economy, forthcoming.

5. Bowlin, Oswald D. "The Refunding Decision: Another Special Case in Capital Budgeting." Journal of Finance, XXI (March, 1966), 55-68.

6. Brennan, Michael J., and Schwartz, Eduardo S. "Savings Bonds, Retractable Bonds, and Callable Bonds." Journal of Financial Economics, forthcoming.

7. Cyert, Richard M., and De Groot, M. H. "Bayesian Analysis and Duopoly Theory." Journal of Political Economy, LXXVIII (September/October, 1970), 1168-1184.

8. Cyert, Richard M., and De Groot, M. H. "Multiperiod Decision Models with Alternating Choice as a Solution to the Duopoly Problem." Quarterly Journal of Economics, LXXXIV (August, 1970), 410-429.

9. Elton, Edwin J., and Gruber, Martin J. "The Economic Value of the Call Option." Journal of Finance, XXVII (September, 1972), 891-901.

10. Elton, Edwin J., and Gruber, Martin J. Finance as a Dynamic Process. Englewood Cliffs: Prentice-Hall, 1975.

11. Hess, Arleigh P., Jr., and Winn, Willis J. The Value of the Call Privilege. Philadelphia: University of Pennsylvanie, 1962.

12. Hicks, John R. Value and Capital. London: Oxford University Press, 1939.

13. Jen, Frank C., and Wert, James E. "The Effect of Call Risk on Corporate Bond Yields." Journal of Finance, XXII (December, 1967), 637-651.

14. Kalymon, Basil A. "Bond Refunding with Stochastic Interest Rates." Management Science, XVIII (November, 1971), 171-183.

15. Karlin, Samuel. "Stochastic Models and Optimal Policy for Selling an Asset." Arrow, Karlin and Scarf (eds.), Studies in Applied Probability and Management Science. Stanford: Stanford University Press, 1962. 
16. Kraus, Alan. "The Bond Refunding Decision in an Efficient Market." Journal of Financial and Quantitative Analysis, VIII (December, 1973), 793-806.

17. Lutz, Friedrich A. "The Structure of Interest Rates." quarterly Journal of Economics, LIV (November, 1940), 36-63.

18. Merton, Robert C. "On the Pricing of Corporate Debt: The Risk Structure of Interest Rates." Journal of Finance, XXIX (May, 1974), 449-470.

19. Ofer, Aharon R., and Taggart, Robert A., Jr. "Bond Refunding: A Clarifying Analysis." Journal of Finance, XXXII (March, 1977), 21-30.

20. Pye, Gordon. "The Value of the Call Option on a Bond." Journal of Political Economy, LXIV (April, 1966), 200-205.

21. Pye, Gordon. "The Value of Call Deferment on a Bond: Some Empirical Results." Journal of Finance, XXII (December, 1967), 623-636. 